\title{
ECONOMIA POLÍTICA DO TRABALHO NA ERA LULA: UMA ANÁLISE DA EXPERIÊNCIA RECENTE DE MELHORIA NAS CONDIÇÕES DE OCUPAÇÃO DA FORÇA DE TRABALHO NO BRASIL
}

\author{
LULA'S BRAZIL POLITICAL ECONOMY OF LABOR: AN ANALYSIS OF BRAZILIAN \\ RECENT EXPERIENCE OF IMPROVEMENT IN LABOR OCCUPATION CONDITIONS
}

\author{
Vinicius Lobo ${ }^{1}$ \\ Viviani Anze ${ }^{2}$ \\ Felipe Pateo ${ }^{3}$
}

\section{RESUMO}

Este artigo aborda a dinâmica da estrutura ocupacional brasileira entre 2003 e 2014. Pretende explicar por que, nesse período, viveu-se uma surpreendente e intensa melhoria nas condições de ocupação e se propõe a fazê-lo por meio da análise da gênese político-econômica das tendências que, dentro do mercado de trabalho, foram determinantes para essa melhoria. A principal constatação a que chega essa análise é a de que o perfil de variação da demanda agregada foi decisivo, pois estimulou uma composição particular de acumulação de capital, intensiva na participação do fator trabalho, e isso, por sua vez, promoveu o agudo crescimento do emprego com carteira assinada que esteve por trás das duas principais tendências que, dentro do mercado de trabalho, promoveram a melhoria no padrão de ocupação.

Palavras-Chave: estrutura ocupacional, mercado de trabalho, acumulação de capital, composição da demanda, distribuição de renda.

\begin{abstract}
This article tackles workforce occupation problematic in Brazilian economy from 2003 to 2014. Intents to explain why a surprising and intense improvement in workforce occupation conditions erupted in this period and proposes to do it by analyzing political-economical origins of tendencies that, inside the labor market, were decisive for its improvement. The main achievement of this article is that aggregate demand profile was decisive, because it stimulated a particular composition inside capital accumulation, labor intensive, what promoted a strong process of formal job creation on the private sector, process which was the essential cause of the improvement in workforce occupation.
\end{abstract}

Keywords: workforce occupation, labor market, capital accumulation, composition of demand, income distribution.

\footnotetext{
${ }^{1}$ Mestre em Sociologia pelo Programa de Pós-Graduação em Sociologia da Universidade Federal de Pernambuco (PPGS-UFPE) e membro da carreira de desenvolvimento de políticas sociais, lotado na Superintendência Regional do Trabalho em Pernambuco.

${ }^{2}$ Mestranda em Economia Regional do Instituo de Economia da Universidade de Campinas (IE-UNICAMP) e membro da carreira de desenvolvimento de políticas sociais, lotado na Superintendência Regional do Trabalho em São Paulo.

${ }^{3}$ Doutorando em Estudos Latino-Americanos do Departamento de Estudos Latino-Americanos da Universidade de Brasília (ELA-UnB) e membro da carreira de desenvolvimento de políticas sociais, lotado na Secretaria de Políticas Públicas de Emprego.
} 


\section{INTRODUÇÃO}

Durante quase trinta anos, acompanhar os indicadores sociais do Brasil era um exercício contínuo de frustração. De meados dos anos 1970 até o final dos anos 1990, os indicadores de pobreza e distribuição de renda apresentaram, conforme o título do artigo hoje clássico para os estudos sobre desigualdade e políticas sociais no Brasil, de Barros, Henrique e Mendonça (2000), uma estabilidade inaceitável ${ }^{4}$. Entre 1975 e 1999, a desigualdade manteve-se impassível no mesmo patamar (0,60 do coeficiente de Gini) e a pobreza, apesar de duas pequenas contrações nos momentos de implantação dos planos Cruzado e Real, permaneceu num nível bastante elevado, de 33\% (BARROS, 2000, p.124). Reproduzia-se, assim, na sociedade brasileira, mesmo com o país enriquecendo e a economia crescendo em média quase 5\% ao ano, uma irredutível lógica de exclusão e marginalização social, a qual, dada a sua firmeza e a sua longevidade, parecia longe de dissipar-se. Sedimentava-se a impressão de um Brasil cronicamente inviável.

No inicio dos anos 2000, portanto, as expectativas não eram muito animadoras do ponto de vista do desenvolvimento social. No entanto, o que se vivenciou nesse período, sobretudo entre 2004 e 2013, foi um notável processo de distribuição de renda e inclusão social, num ritmo e numa regularidade que não se via desde os anos dourados do trabalhismo, na década de 1950. O Gini cai continuamente, saindo de 0,581 em 2003 para 0,515 em 2014, uma magnitude de queda inédita, assim como as taxas de pobreza e pobreza extrema, que, respectivamente, saíram de $12,35 \%$ e $24,9 \%$ em 2003 para $3,90 \%$ e 8,54\% em $2014^{5}$. Os resultados destacam-se não só pela magnitude e regularidade, mas também pelo contraste com a estagnação que vigorara anteriormente.

Analisar esse período, em que houve esse surpreendente processo - intenso e contínuo - de inclusão social é o que se propõe neste artigo. E a proposta aqui é realizar uma análise do ponto de vista da ocupação da força de trabalho, mais especificamente das razões por detrás da melhoria no padrão de ocupação, pois, como resta hoje evidente ${ }^{6}$, a base desse processo inclusivo foi uma melhoria sistemática nas condições de ocupação da população.

Este artigo aborda, portanto, a dinâmica da estrutura ocupacional brasileira durante os anos 2003-2014 - período que chamaremos aqui de Era Lula ${ }^{7}$, quando as condições de

\footnotetext{
${ }^{4}$ A estabilidade inaceitável: desigualdade e pobreza no Brasil. Outro trabalho central para se entender a dinâmica da desigualdade e da pobreza dos anos 1970 aos 1990 é o de Hoffmann (1998), Desigualdade e pobreza no Brasil no período $1979 / 97$ e a influência da inflação e do salário mínimo. Cf. também Dynamics of income distribution in Brazil, de Neri (1997).

5 Para mais informações sobre desigualdade e pobreza entre 2003 e 2014, cf. Calixtre e Vaz (2015), Nota Técnica n ${ }^{\circ} 22$, do Instituo de Pesquisa Econômica Aplicada (IPEA).

${ }^{6}$ Está hoje evidente a relação de dependência entre a queda da desigualdade e da pobreza e a as condições de ocupação dos trabalhadores. Em relatório que trata do desenvolvimento social vivenciado na América Latina nos anos 2000, a CEPAL aponta que o perfil do trabalho foi o fator decisivo na obtenção dos avanços no combate à pobreza e à desigualdade na região (CEPAL, 2015, p.35-36). Para Fagnani e Calixtre é "crucial observar que um dos motivos determinantes desse fenômeno [queda da desigualdade e da pobreza] foi não apenas ter trazido o Estado de volta para a equação do desenvolvimento, ao tempo em que também priorizou as demandas do mercado de trabalho" (FAGNANI e CALIXTRE, 2017, p.32). Em trabalho publicado pelo IPEA, Cardoso Jr e Hamasaki, apontam uma forte correlação entre distribuição/mobilidade social e a estruturação do mercado de trabalho (CARDOSO JR e HAMAZAKI, 2014, p.45). Neri, em A década inclusiva: 2001-2011(NERI, 2013, p.05), aponta que $80 \%$ da inclusão deveu-se à melhoria das condições de trabalho, enquanto a Previdência Social e o Bolsa Família respondem por praticamente todo o os outros $20 \%$.

7 Em sua classificação, Barbosa defende que a Era Lula "não se refere apenas ao governo Lula, mas a um conjunto de movimentos por ele detonados, os quais geram ações e reações por parte da sociedade, vice-versa" (BARBOSA, 2014, p.135). O autor não atribui um período a tal "Era", mas optamos por fazê-lo porque o movimento que em particular aqui se analisa, uma determinada tendência no padrão de ocupação da força de trabalho, ainda que, por escolhas político-econômicas, entre em retração sob a gestão da ex-presidente Dilma, mantêm-se predominante ao longo de quase todo o seu primeiro mandato.
} 
ocupação da força de trabalho apresentaram uma notável melhoria e, assim, promoveram um amplo e intenso processo de inclusão social. É esse o seu objeto. Seu objetivo é apresentar elementos que ajudem a explicar essa melhoria.

Compreendem a estrutura do texto, além dessa introdução, três seções. A primeira apresenta a referida melhoria em seus principais elementos; a segunda analisa suas causas a partir das tendências dominantes no âmbito do mercado de trabalho e da relação dessas tendências com a dinâmica político-econômica; e a terceira conclui o texto, apresentando o que se considera as suas principais constatações.

\section{OS PRINCIPAIS PONTOS DE MELHORIA NAS CONDIÇÕES DE OCUPAÇÃO ${ }^{8}$}

Em linha com o que tem sido apresentado em algumas pesquisas ${ }^{9}$, defende-se aqui que foi basicamente através de quatro processos que a melhoria nas condições de ocupação se apresentou à população durante a Era Lula: (a) da queda na desocupação; (b) do aumento da remuneração real; (c) do aumento da proteção social; e (d) do aumento da participação das relações de emprego em estabelecimentos comerciais ${ }^{10}$. A seguir apresentaremos esses resultados e, a fim de deixar expressa a sua magnitude, faremos uma comparação com os resultados dos doze anos imediatamente anteriores, isto é, entre 1992 e 2003 (a Tabela 01 expõe esses resultados de maneira compilada).

Tabela 01- Resultados em 1992, 2003, 2014, variação absoluta entre 92 e 03, variação absoluta entre 03 e 14 e variação relativa da variação absoluta entre 92-03 e 03-14 da desocupação, renda média mensal, formalidade do emprego e total e do emprego em estabelecimento e sua part. na PO.

\begin{tabular}{|c|c|c|c|c|c|c|c|}
\hline & & 1992 & 2003 & 2014 & $\Delta 92 \rightarrow 03$ & $\Delta 03 \rightarrow 14$ & $\Delta(\Delta 03-14) \rightarrow(\Delta 92-03)$ \\
\hline \multicolumn{2}{|c|}{ Desocupação (\%) } & $6,66 \%$ & $10,00 \%$ & $7,2 \%$ & $3,34 \%$ & $-2,80 \%$ & $-183,83 \%$ \\
\hline \multirow{8}{*}{$\begin{array}{c}\text { Renda } \\
\text { Média } \\
\text { Mensal } \\
\text { (R\$) }\end{array}$} & $\mathrm{PO}$ & $1.306,34$ & $1.374,12$ & $1.968,12$ & 67,78 & 594,00 & $776,37 \%$ \\
\hline & Emp. c/ carteira & $1.567,32$ & $1.473,27$ & $1.893,37$ & $-94,05$ & 420,10 & $546,68 \%$ \\
\hline & Emp. s/ carteira & 628,95 & 808,51 & $1.284,54$ & 179,56 & 476,03 & $165,11 \%$ \\
\hline & Conta própria & $1.066,70$ & $1.127,22$ & $1.719,23$ & 60,52 & 592,01 & $878,21 \%$ \\
\hline & Empregador & $3.986,86$ & $4.461,45$ & $5.976,43$ & 474,59 & $1.514,98$ & $219,21 \%$ \\
\hline & Dom. c/ carteira & 567,63 & 656,34 & $1.069,80$ & 88,71 & 413,46 & $366,05 \%$ \\
\hline & Dom. s/ carteira & 318,25 & 390,20 & 677,76 & 71,95 & 287,56 & $299,66 \%$ \\
\hline & Emp. Público & $1.955,27$ & $2.388,49$ & $3.484,12$ & 433,22 & $1.095,63$ & $152,91 \%$ \\
\hline \multicolumn{2}{|c|}{ Formalidade do Emprego (\%) } & $65,59 \%$ & $63,99 \%$ & $73,32 \%$ & $-1,60 \%$ & $9,33 \%$ & $683,12 \%$ \\
\hline \multicolumn{2}{|c|}{ Formalidade Total (\%) } & $43,00 \%$ & $46,00 \%$ & $61,00 \%$ & $3,00 \%$ & $15,00 \%$ & $400 \%$ \\
\hline \multicolumn{2}{|c|}{ Emp. em Estab. } & 33.296 .732 & 43.623 .141 & 59.960 .322 & 10.326 .409 & 16.337 .181 & $58,20 \%$ \\
\hline \multicolumn{2}{|c|}{ Part. Emp. em Estab. na PO } & $53,00 \%$ & $54,00 \%$ & $62,00 \%$ & $1,00 \%$ & $8,00 \%$ & $700,00 \%$ \\
\hline
\end{tabular}

Fonte: PNAD/IPEA. Elaboração Própria.

A taxa de desocupação (a) saiu, segundo a PNAD/IBGE, de 10\% em 2003 para 7,2\% em 2014, passando pela mínima de 6,4\% em 2012. Eram 8.755.637 de desocupados em 2003 e 7.444.634 em 2014, 1.311.003 a menos. O contraste com os doze anos anteriores é forte,

\footnotetext{
${ }^{8}$ Todas as informações da Pesquisa Nacional de Amostra por Domicílios do Instituo Brasileiro de Geografia e Estatística (PNAD/IBGE) apresentadas nesta e na próxima seção nos foram cedidas pela Diretoria de Estudos e Políticas Sociais (DISOC) do IPEA, a quem somos gratos pelo apoio, sempre.

${ }^{9}$ Medeiros (2015), Baltar e Leone (2012), Barbosa Filho e Moura (2012) e Krein et al (2010).

${ }^{10}$ Aqui não entra o trabalho doméstico, forma de emprego de força de trabalho sem fim mercantil ou comercial.
} 
ente 1992 e 2003 a taxa de desocupação saiu de 6,7\% para 10\%, com o número de desocupados mais do que dobrando, passando de 4.201.008 para 8.755.637. Enquanto a taxa de desocupação caiu quase 3p.p. entre 2003 e 2014, ela aumentou mais de 3p.p. entre 1992 e 2003. Temos, assim, comparando essas duas variações, uma grande diferença de magnitude entre os resultados de cada período, da ordem de $-183,83 \%$, ou seja, a diferença na luta contra a desocupação foi de quase $185 \%$ entre os dois períodos.

Quanto à (b) remuneração, o principal indicador de mensuração é a renda média real mensal dos ocupados, pois expressa a média do rendimento mensal bruto auferido pelo trabalhador. Consiste na média, por pessoa ocupada, dos rendimentos mensais brutos totais em dinheiro recebidos em todos os trabalhos. Segundo a PNAD/IBGE, a renda real média mensal da população ocupada (PO), a preços de 2015, saiu de R \$ 1.374,12 em 2003 para R\$ 1.968,12 em 2014, um aumento real de $\mathrm{R} \$ 594$, que corresponde a um ganho de 43,22\%. É interessante analisar esses resultados a partir de uma desagregação pela posição na ocupação dos indivíduo, entre os empregados com carteira assinada houve aumento de R\$420,19 (28,55\%); entre os empregados sem carteira de $\mathrm{R} \$ 474,03$ (58,87\%); entre os trabalhadores por conta própria de $\mathrm{R} \$ 592,01$ (52,51\%); entre os empregadores de $\mathrm{R} \$ 1.514,98$ (33,95\%); entre os domésticos com carteira de R \$ 413,46 (62,99\%); entre os domésticos sem carteira de $\mathrm{R}$ \$ 287,56 (73,11\%); e entre os empregados públicos de $\mathrm{R} \$ 1.095,63$ (45,87\%).

O que fica claro ao observar essa desagregação, é que houve um ganho real generalizado, com um ganho relativo maior nas posições mais precárias, quais sejam, os domésticos com e sem carteira, os empregados sem carteira e os trabalhadores por conta própria. Os empregados com carteira, posição na ocupação que, como se verá a frente, mais criou oportunidades no período, apresentou ganhos sólidos. Ao comparar esse período com os doze anos anteriores, mais uma vez surge uma forte diferença de magnitude na variação. Entre 1992 e 2003, a renda média real da população ocupada teve ganho real de $\mathrm{R} \$ 67,76$, o que faz do resultado entre 2003 e 2014 muito maior (776,37\%). Olhando mais uma vez para as posições na ocupação, a renda real mensal dos empregados com carteira assinada, dos empregados sem carteira, dos conta própria, dos empregadores, dos domésticos com carteira, dos domésticos sem carteira e dos empregados públicos variou, respectivamente, R $\$-94,05$ (547\%), $\mathrm{R} \$ 179,56$ (165\%), $\mathrm{R} \$ 60,53$ (878\%), $\mathrm{R} \$ 474,59$ (219\%), $\mathrm{R} \$ 88,71$ (366\%), $\mathrm{R} \$ 71,95$ (300\%), o que faz dos resultados do de 2003-2014 muito maiores, sobretudo entre os empregados com carteira e os conta própria.

Em relação à (c) proteção social, é preciso considerar a formalização tanto de empregados em estabelecimento quanto de todas as formas de ocupação. Em 2003 a taxa de formalidade entre os empregados era de $63,99 \%$, ao passo que, em 2014 , a mesma passou a $73,32 \%(+9,33 \%)$. Esse aumento foi resultado de um forte crescimento na oferta de emprego formal (14.633.128 vagas a mais) e de uma leve queda na oferta de emprego informal (53.940 vagas a menos). Levando-se em consideração a contribuição de todos os ocupados à previdência social, forma de avaliar a proteção social independentemente da posição na ocupação, também se constata um significativo crescimento: o total de contribuintes passou de $46 \%$ em 03 para $61 \%$ em $14(+15 \%)$.

Esses números também indicam um significativo avanço no campo da proteção social do trabalho. Comparando com o período 92-03, a mesma diferença de magnitude previamente observada aparece. Em relação a contribuição à previdência, ela era de 43\% em 1992 e passou a $46 \%$ em 2003, uma variação de 3\%, o que faz do resultado na Era Lula $400 \%$ maior. Já em relação à formalidade dos empregos, a mesma diminuiu de 1992 a 2003, passou de 65,59\% para $63,99 \%$, uma queda de $2,6 \%$, o que leva o resultado da Era Lula a ser $683 \%$ maior. Tal queda deveu-se a um crescimento do emprego informal (4.064.923 vagas a mais) equiparado ao do emprego formal (4.879.610 vagas a mais). 
O último processo através do qual se manifestou a melhoria nas condições de ocupação vivenciada na Era Lula foi no (d) aumento das relações de emprego em estabelecimentos comerciais. Entre 2003 e 2014, o total de empregados passou de 43.623.141 para 59.960.322 (+16.337.181). Tal variação representa um importante crescimento, contudo, o mais significativo aqui é o aumento na participação dos empregados na PO, que saiu de $54 \%$ para $62 \%(+8 \%)$, o que foi resultado tanto do sólido ritmo de crescimento do emprego quanto do baixo ritmo de crescimento das posições não assalariadas e do trabalho doméstico. Os trabalhadores por conta própria, não-remunerados e domésticos, variaram, respectivamente, $14 \%,-51 \%$ e $5 \%$, o que corresponde a um ritmo muito inferior em relação aos empregados, com destaque para a queda no trabalho não remunerado e para baixíssima variação do doméstico. Comparando esses resultados com os do período 1992-2003, mais uma vez, destaca-se uma forte diferença de magnitude. Nesse período, a participação dos empregados variou apenas $1 \%$, passando de $53 \%$ para $54 \%$ (o que faz da variação da Era Lula $700 \%$ maior), o que se deu, não pelo ritmo de crescimento dos empregos (+10.326.409), mas pelo ritmo de crescimento das posições não-assalariadas: ocupados por conta própria, nãoremunerados e no trabalho doméstico, variaram, respectivamente, $29 \%$, $4 \%$ e $51 \%$.

Para finalizar essa seção, é importante destacar ainda que, além de uma grande diferença de magnitude, outro ponto que destoa entre os resultados dos anos 03-14 e 92-03, é a existência, entre 2003 e 2014, de uma trajetória contínua de melhoria dos indicadores, ao passo que entre 1992 e 2003 essa trajetória é intermitente, inverte mais de uma vez a relação de ordem, oscilando momentos de alta e de queda. Há, assim, também uma diferença de relação de ordem entre os dois períodos, um (no geral) preservando e o outro invertendo a relação de ordem dos resultados.

\section{RAZÕES DA MELHORIA NO PADRÃOO DE OCUPAÇÃO DA FORÇA DE TRABALHO}

Apresentada a melhoria da ocupação em seus principais elementos, passa-se agora à análise das suas razões, ou melhor, daquilo que a causou. O que aconteceu para que as condições de ocupação pudessem melhorar dessa maneira?

Para nós, a resposta a essa pergunta deve ser procurada na dinâmica do mercado de trabalho e de sua cadeia causal. A dinâmica da oferta e da procura de força de trabalho está, para nós, na raiz das condições de ocupação. Tal dinâmica, contudo, como discutiremos um pouco a frente, é resultado do desenvolvimento da produção capitalista, ou seja, da acumulação de capital e dos seus determinantes, por isso, se nosso objetivo é chegar às causas da melhoria da ocupação, não podemos permanecer apenas nos resultados do mercado de trabalho, é preciso adentrar no processo político-econômico que os desencadeia. É preciso, deste modo, aprofundar-se também na lógica da acumulação e dos fatores políticoeconômicos que a determinam.

Assim, a proposta aqui é explicar a melhoria na ocupação através da exposição da gênese político-econômica das tendências que, dentro do mercado de trabalho, foram determinantes para a melhoria das condições de ocupação. E propomos fazer isso em três etapas ou subseções: primeiro, identificando as principais tendências do mercado de trabalho; depois, analisando o perfil da acumulação de capital no período; e, por último, identificando a lógica político-econômica que promoveu esse perfil.

\section{Principais tendências do mercado de trabalho}

As teorias econômicas são geralmente elaboradas num alto grau de abstração e apresentam divergências analíticas significativas, sobretudo quando o assunto é trabalho e 
renda. No entanto, mesmo as posições mais antagônicas concordam em relação a um aspecto, absolutamente imanente à vida econômica na moderna sociedade de mercado, que é a influência da relação entre oferta e demanda no valor de uma mercadoria, a famosa lei da oferta e da procura. E o trabalho, nesse tipo de sociedade, é uma mercadoria tal qual as demais, por isso, tem o seu valor ou o seu preço de venda determinado pela relação entre oferta e procura. O preço do trabalho é influenciado, portanto, da mesma forma que o preço de qualquer mercadoria, pela concorrência entre os compradores e vendedores. De acordo com cada vertente teórica, essa influência opera de maneira diferente, pois cada uma defende sua operação em cima de bases político-econômicas específicas, como veremos brevemente logo adiante, mas é universal o reconhecimento de que a relação entre oferta e procura é decisiva para a remuneração e condições de realização do trabalho ${ }^{11}$.

Nesta subseção, tentaremos identificar as tendências do mercado de trabalho que influenciaram as condições de ocupação a partir dessa perspectiva mais genérica, dada pela lei da oferta e da procura. É partir de tal perspectiva que observaremos, agora, os rumos do mercado de trabalho e julgaremos quais movimentos podem ter influenciado as condições de ocupação.

No caso deste mercado em particular, da mercadoria trabalho, a oferta é dada de maneira direta pela população economicamente ativa (PEA), que é o total de pessoas dispostas a trabalhar num determinado momento do tempo, estejam elas ocupadas ou não. É a força de trabalho imediatamente disponível (RAMOS, 2012, p.33). Já em relação à demanda, como vimos na seção anterior, na economia brasileira, há diferentes formas de ocupação, a maioria delas não vinculada a estabelecimentos comerciais que recrutam mão-de-obra no mercado de trabalho. A demanda de trabalho precisa assim ser abordada de uma maneira mais ampla, indo além do emprego, o que será feito aqui, de momento, seguindo a um conceito que tem sido utilizado por Baltar e Leone, o de oportunidade ocupacional. Conforme colocam os autores:

[...] a avaliação desse aspecto [o do emprego ou da demanda por trabalho] do desempenho da economia brasileira no período [...] deve situar a geração de empregos em um contexto mais amplo: o da absorção da PEA em diferentes tipos de oportunidades ocupacionais decorrentes da atividade econômica (BALTAR e LEONE, 2015, p.54).

E a oferta total de oportunidades ocupacionais está dada nos resultados da população ocupada (PO). A tabela 02 expõe a evolução da oferta e da procura de trabalho, de acordo com os conceitos expostos no parágrafo acima.

Tabela 02- Resultados em 1992, 2003, 2014, variação absoluta e relativa entre 92 e 03 e 03 e 14 e variação relativa da variação absoluta entre 92-03 e 03-14 da PO e da PEA.

\begin{tabular}{|c|c|c|c|c|c|c|}
\hline & 1992 & 2003 & 2014 & $\Delta 92 \rightarrow 03$ & $\Delta 03 \rightarrow 14$ & $\Delta(\Delta 03 \rightarrow 14) \rightarrow(\Delta 92 \rightarrow 03)$ \\
\hline $\begin{array}{c}\text { População } \\
\text { Ocupada (PO) }\end{array}$ & 61.669 .263 & 79.036 .478 & 96.848 .803 & $\begin{array}{c}17.367 .215 \\
(+28,16 \%)\end{array}$ & $\begin{array}{c}17.812 .325 \\
(+22,54 \%)\end{array}$ & $2,56 \%$ \\
\hline $\begin{array}{c}\text { População } \\
\text { Economicamente } \\
\text { Ativa (PEA) }\end{array}$ & 65.897 .145 & 87.557 .348 & 104.058 .896 & $\begin{array}{c}21.660 .203 \\
(+32,87 \%)\end{array}$ & $\begin{array}{c}16.501 .548 \\
(+18,84 \%)\end{array}$ & $-23,82 \%$ \\
\hline
\end{tabular}

Fonte: PNAD/IPEA. Elaboração Própria.

\footnotetext{
${ }^{11}$ Enfatiza-se que a lei da oferta e da procura é apenas um dos aspectos que determinam o preço de venda (ou a remuneração do trabalhador), aspecto que é reconhecido por quase todas as correntes teóricas, apesar de cada uma atribuir outras determinações, de acordo com a sua vertente. Destacamos também que o peso da lei da oferta e da procura é maior sobre a remuneração dos trabalhadores menos qualificados.
} 
Entre 2003 e 2014, segundo a PNAD/IBGE, o número de pessoas ocupadas expandiuse $22,54 \%$, com a criação de 17.812 .325 novas oportunidades de ocupação, um crescimento médio anual de $1,87 \%$. Quando se coloca essa ampliação em relação com o crescimento do produto (PIB), que cresceu 42\% entre 2003 e 2014, tem-se uma relação de elasticidade ocupação-produto de $0,54 \%$. Vis-à-vis a expansão da PO e a elasticidade ocupação-produto do período $92-03$, de, respectivamente, $28,16 \%$ (2,56\% ao ano) e $0,94 \%$ (resultado da relação entre $28,06 \%$ de crescimento da PO e 30,06\% de crescimento do PIB), os resultados da demanda por trabalho, no período $03-14$, podem ser considerados relativamente modestos e pouco eficazes.

Assim, do ponto de vista do total de oportunidades de ocupação, a atividade econômica expandiu de maneira modesta e pouco eficaz a demanda por trabalho entre $2003 \mathrm{e}$ 2014. À luz da lei da oferta e da procura e da melhoria observada nas condições de ocupação, uma expansão modesta como essa pode parecer estranha, contudo, nesse período, viveu-se uma queda na taxa de participação, o que fez com que a PEA crescesse num ritmo mais lento que o da PO. A taxa de participação é a razão entre PEA e PIA, ou seja, o "percentual da população que potencialmente poderia participar do mercado de trabalho e realmente o faz" (RAMOS, 2012, p.61). Entre 2003 e 2013, a taxa de participação sai de 67,8\% para 65,4\% (queda de 2,4\%), subindo para 66,4\% em 2014, já sofrendo os efeitos da crise econômica (entre 1992 e 2003 , a mesma saiu de $68,4 \%$ para $67,8 \%$, queda de $0,6 \%$ ).

Graças a essa queda, a PEA vai se expandir apenas $18,84 \%$ no período, com a entrada de 16.501.548 novas pessoas dispostas a trabalhar, um crescimento médio de $1,57 \%$ ao ano. Um ritmo de ampliação que pode ser considerado bastante lento vis-a-vis o ritmo de ampliação da PEA nos doze anos imediatamente anteriores, da ordem de 32,87\% (2,74\% ao ano). Deste modo, entre 2003 e 2014, com base na evolução da PEA, pode-se afirmar que a oferta de trabalho se expandiu de maneira muito modesta.

Olhando esses movimentos da PO e da PEA no mercado de trabalho, somos levados a inferir que o ritmo de crescimento da segunda teve um papel decisivo no processo de melhoria das condições de ocupação no período 03-14, já que a demanda, dada pelo conceito de oportunidade ocupacional, cresceu num ritmo mais modesto, mas similar ao do período 9203. Nesses anos 1992-2003, mesmo com uma expansão um pouco mais forte das oportunidades ocupacionais, as condições de ocupação se deterioraram, com a PEA crescendo mais forte do que PO. Conforme mostra Tabela 02, os resultados em nível de demanda (PO) ficam praticamente estáveis entre os dois períodos, já em nível de oferta (PEA), há uma queda de quase $24 \%$.

Uma interessante estimativa feita por Baltar e Leone (2015) ajuda a deixar ainda mais ilustrada a importância do ritmo de crescimento PEA entre 2003 e 2014. Para eles:

A importância da queda na taxa de participação [e, consequentemente, do ritmo de crescimento da PEA] é ilustrada estimando o que teria ocorrido com o desemprego caso a ampliação verificada das oportunidades ocupacionais tivesse sido acompanhada de crescimento da PEA no mesmo ritmo do crescimento da PIA. Nesse pressuposto, o número de desempregados aumentaria $10,2 \%$ no período e a taxa de desemprego diminuiria de $9,1 \%$ para $8,8 \%$, uma redução muito menor do que a realmente verificada [de $9,1 \%$ para $6,6 \%$ ]. Já no caso da população ocupada se ampliar em um ritmo de $1,75 \%$, mantendo a mesma taxa de participação de 2004 em 2013, ocorreria uma redução do número de desempregados de 13\%, com a taxa de desemprego diminuindo de 9,15 para $7 \%$, no período. Ou seja, uma ampliação mais intensa das oportunidades ocupacionais não teria provocado queda tão importante na taxa de desemprego, como a realmente verificada, a partir do crescimento mais modesto da população ocupada e diminuição da 
taxa de participação [com sua consequência direta da diminuição no ritmo de crescimento da PEA]. (BALTAR e LEONE, 2015, P. 55-56)

Assim, para Baltar e Leone, a queda da taxa de participação e a sua influência no crescimento da PEA "fez com que a [mesmo] modesta ampliação das oportunidades ocupacionais provocasse uma expressiva redução, de 18,8\%, no número de pessoas desempregadas, fazendo a taxa de desemprego diminuir de $9,1 \%$ em 2004 para $6,6 \%$ em 2013" (BALTAR e LEONE, 2015, p.55). Não houvesse tal movimento no âmbito da oferta de trabalho, como ilustrado pela estimativa citada acima, teríamos um contingente maior de desempregados pressionando o mercado de trabalho, o que, consequentemente, influenciaria de maneira negativa as condições de ocupação.

A queda na taxa de crescimento da PEA foi, deste modo, uma tendência determinante para a melhoria no padrão de ocupação. Temos aqui, portanto, uma clara determinação, pelo lado da oferta de trabalho. Contudo, tal fato não deve nos levar a deixar de lado a evolução da demanda (PO), pois, apesar desta última ter crescido de maneira modesta, também foi decisiva para a melhoria da estrutura ocupacional. E isso ocorreu porque, apesar de quantitativamente modesta, a demanda por trabalho teve, entre 2003 e 2014, uma notável evolução do ponto de vista qualitativo. É preciso, agora, por conseguinte, deixar de considerar a ocupação de maneira uniforme, sob o conceito de oportunidade ocupacional, e atentar para a natureza do crescimento da PO (Tabela 03 e Gráfico 02), algo que, inclusive, já foi introdutoriamente observado na primeira seção.

Tabela 03- Resultados em 1992, 2003, 2014, variação absoluta entre 92 e 03 e 03 e 14 e variação relativa da variação absoluta entre 92-03 e 03-14 de todas as formas de ocupação.

\begin{tabular}{|c|c|c|c|c|c|c|}
\hline & 1992 & 2003 & 2014 & $\Delta 92 \rightarrow 03$ & $\Delta 03 \rightarrow 14$ & $\Delta(\Delta 03 \rightarrow 14) \rightarrow(\Delta 92 \rightarrow 03)$ \\
\hline Emp.c/ carteira & 19.249 .479 & 24.129 .089 & 38.762 .217 & 4.879 .610 & 14.633 .128 & $200 \%$ \\
\hline Emp.s/ carteira & 10.097 .067 & 14.161.990 & 14.108 .041 & 4.064 .923 & -53.949 & $-101 \%$ \\
\hline Conta própria & 13.950 .387 & 17.925 .757 & 20.465 .642 & 3.975 .370 & 2.539 .885 & $-36 \%$ \\
\hline Empregador & 2.399 .024 & 3.383 .403 & 3.694 .250 & 984.379 & 310.847 & $-68 \%$ \\
\hline Ñ remunerado & 4.917 .970 & 4.698 .206 & 2.300 .730 & -219.764 & -2.397 .476 & $-991 \%$ \\
\hline Dom. c/ carteira & 754.171 & 1.675 .835 & 2.051 .547 & 921.664 & 375.712 & $-59 \%$ \\
\hline Dom. s/ carteira & 3.281 .915 & 4.420 .915 & 4.341 .616 & 1.139 .000 & -79.299 & $-107 \%$ \\
\hline Emp. Público & 3.950 .186 & 5.332 .062 & 7.090 .064 & 1.381 .876 & 1.758 .002 & $27 \%$ \\
\hline
\end{tabular}

Fonte: PNAD/IPEA. Elaboração Própria

Gráfico 01- Variação absoluta da PO entre 92 e 03 e 03 e 04, por forma de ocupação.

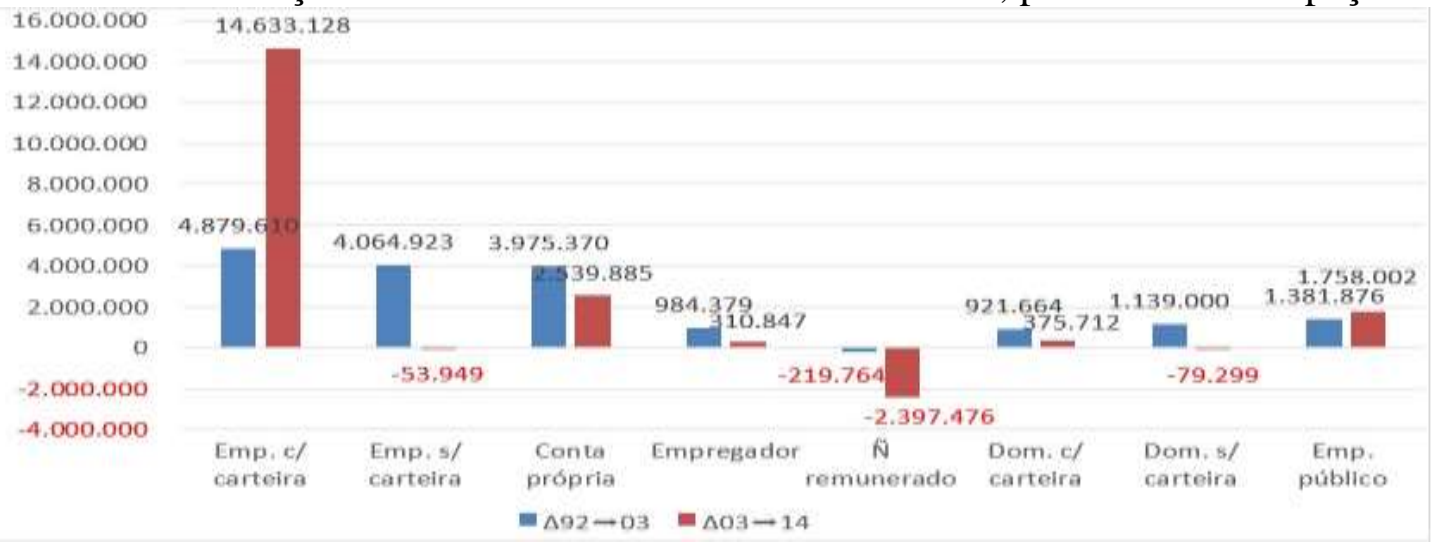

Fonte: PNAD/IPEA. Elaboração Própria

Enquanto no período 92-03 o crescimento da ocupação pulverizou-se entre praticamente todas as formas de ocupação, no período 03-14, esse crescimento concentrou-se 
no emprego com carteira, responsável por $82 \%$ das novas ocupações, ao qual, se somarmos os resultados do emprego público e do trabalho doméstico com carteira, temos o fato de que o emprego formal representou $94 \%$ das oportunidades criadas. Ao mesmo tempo, ocupações mais precárias, como o trabalho não remunerado, o trabalho doméstico sem carteira e o emprego sem carteira contraem-se, e apenas o trabalho por conta própria cresce, mas num ritmo 36\% menor que no período 92-03 e com aumento (como vimos na primeira seção) da sua remuneração e proteção social.

O emprego formal dominou, por conseguinte, quase que por completo, a dinâmica da demanda por trabalho entre 2003 e 2014. Ou como dizem Baltar, Souen e Campos, "o aspecto marcante [...] não foi um aumento desproporcional do total de oportunidades ocupacionais, mas sim o forte crescimento do emprego formal" (BALTAR, SOUEN e CAMPOS, 2017, p.01). A demanda por trabalho na Era Lula foi marcada, portanto, pelo emprego formal. $\mathrm{O}$ impacto disso na melhoria do padrão de ocupação é explícito, já que se trata de ocupações em estabelecimento, com carteira de trabalho assinada ou reguladas por regimes estatutários (e todas as suas garantias de proteção social) e cujo padrão de remuneração é superior a todas as demais posições na ocupação, com exceção apenas dos empregadores. Tivesse esse mesmo predomínio se dado em posições ocupacionais mais precárias, ou caso se tivessem repetidos os resultados dos 12 anos anteriores, em que se destacaram o trabalho doméstico, o trabalho por conta própria e o emprego informal, seriam completamente diferentes os resultados das condições de ocupação. Assim, os resultados em nível de remuneração, proteção social, participação do emprego em estabelecimento e desemprego têm, claramente, relação direta com esse predomínio do emprego formal na expansão da ocupação entre 2003 e 2014.

Temos então, de acordo com a análise feita acima da evolução da PO e da PEA, duas tendências proeminentes na dinâmica do mercado de trabalho entre 2003 e 2014, uma atuando pelo lado da oferta e a outra pelo lado da demanda, ambas no sentido do interesse da parte que vive da sua força de trabalho. Em sua manifestação simultânea reside a melhoria vivenciada no padrão de ocupação da força de trabalho na Era Lula: em conjunto, incidiram sobre o mercado de trabalho um arrefecimento no ritmo de crescimento da oferta de mão de obra e um forte crescimento do emprego formal, ou seja, ao mesmo tempo, multiplicaram-se as boas oportunidades de ocupação e cortou-se o fluxo de pessoas procurando ocupar-se. O gráfico a seguir ajuda a deixar ilustrado o encontro dessas duas tendências, sinérgico para o interesse da classe trabalhadora.

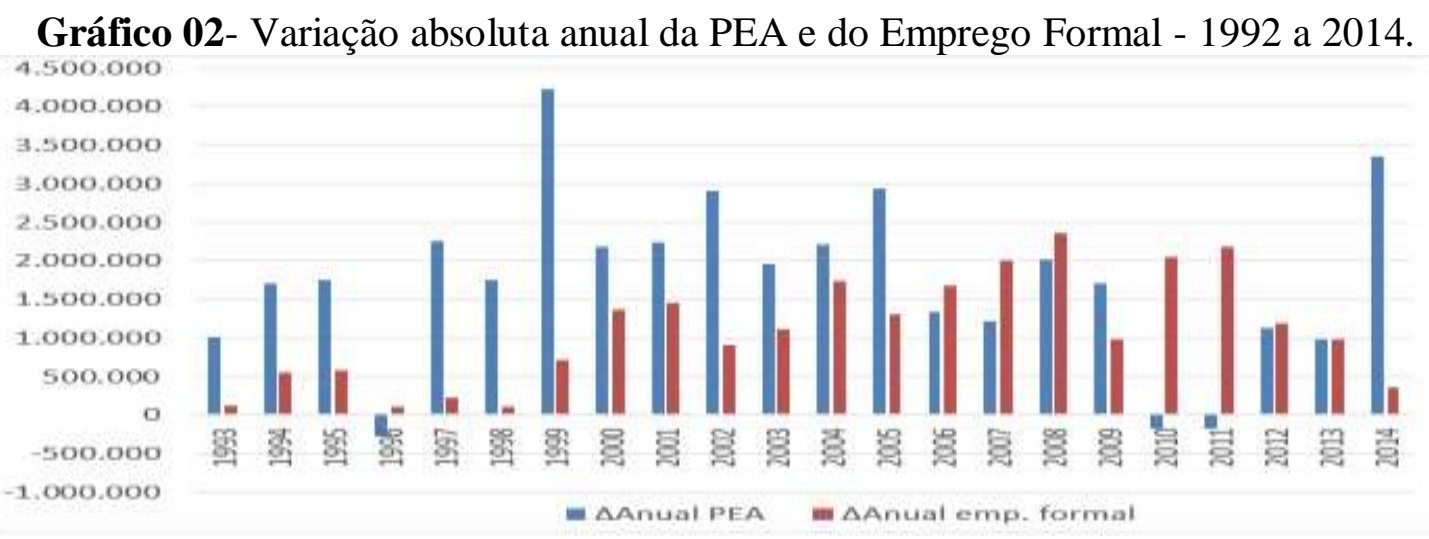

Fonte: PNAD/IPEA. Elaboração Própria.

A melhoria nas condições de ocupação foi, portanto, o resultado da manifestação simultânea, no mercado de trabalho, de um forte crescimento do emprego formal, dominado pelo crescimento do emprego com carteira em estabelecimentos privados, e de uma queda no 
ritmo de crescimento da PEA. Identificadas essas duas grandes tendências, cabe-nos agora examinar suas raízes político-econômicas.

\subsection{Perfil da acumulação de capital}

Conforme sintetizado logo acima, nossa análise do mercado de trabalho indicou que duas tendências foram determinantes para a melhoria nas condições de ocupação entre $2003 \mathrm{e}$ 2014: a queda no crescimento da PEA e o forte crescimento do emprego formal na PO. Essa indicação, apesar de importante, apesar de mostrar qual foi o caminho através do qual as coisas aconteceram no mercado ou espaço concorrencial em que se define a integração das pessoas na atividade produtiva, ainda não é suficiente para explicar a melhoria nas condições de ocupação. É preciso encontrar o que desencadeou essas tendências. É preciso, desse modo, sair do âmbito mais genérico da lei da oferta e da procura, em que nos mantivemos na última subseção, e entrar no espaço mais concreto dos fundamentos político-econômicos, onde se encontram as razões que levaram os agentes do mercado de trabalho a seguir as tendências identificadas acima. Mais especificamente, é preciso adentrar na lógica da acumulação e dos fatores que a determinam.

Ao assumirmos a posição de que a dinâmica do mercado de trabalho depende da acumulação, nos colocamos em linha com o entendimento de Marx, o qual se baseia em algumas das premissas assumidas pelos economistas clássicos que o precederam - Smith, Ricardo e Malthus, como a da influência da oferta e da demanda sobre preço de venda da força de trabalho e a do salário de subsistência ${ }^{12}$, mas se diferencia deles essencialmente por entender o mercado de trabalho como algo subordinado à dinâmica da acumulação capitalista e não à dinâmica da população ${ }^{13}$. Esses autores assumiam a existência de um mecanismo de ajuste demográfico, que levaria a oferta a ajustar-se à demanda a partir de uma associação positiva entre remuneração e crescimento demográfico ${ }^{14}$. Se a demanda por trabalho cresce e assim se elevam os salários, o maior bem-estar permite às famílias serem mais numerosas e assim a população cresce e, consequentemente, a oferta se ajusta à demanda e baixam-se os

\footnotetext{
${ }^{12}$ Conforme coloca Rosdolsky, "Assim como aqueles que o antecederam, Marx também distingue o valor e o preço da força de trabalho (ou, para dizer como os clássicos, o 'preço natural' e o 'preço de mercado' do trabalho) e [...] [também define que] o que determina o valor da força de trabalho [...] são os custos necessários para 'manter o trabalhador como tal' e para 'perpetuar a linhagem dos trabalhadores' [...] a maior parte desses custos é formada pelos meios de vida que servem para conservar o trabalhador e sua família: alimentação, vestuário, habitação etc" (ROSDOLKY, 2011, p.237).

${ }^{13}$ Como coloca Mandel, "Conservando as conclusões da teoria ricardiana dos salários, Marx e Engels a superam amplamente (...) desenvolvem, de fato, uma teoria dos salários que parte, essencialmente, não do movimento demográfico, mas do movimento demográfico da acumulação do capital" (MANDEL apud CAMPOS, 1991, p.144).

${ }^{14}$ Para Smith, "A remuneração generosa do trabalho, possibilitando aos trabalhadores cuidar melhor de seus filhos, e conseqüentemente criar um número maior deles, tende naturalmente a ampliar e estender esses limites. Além disso, cumpre observar que necessariamente faz isso tanto quanto possível, na proporção exigida pela demanda de mão-de-obra. Se essa demanda aumentar continuamente, a remuneração do trabalho necessariamente estimulará o matrimônio e a multiplicação de trabalhadores de tal forma que possa dar-lhes condições para atender a essa demanda em contínuo aumento com uma população cada vez mais numerosa. Se a remuneração em algum momento for inferior ao que se requer para esse fim, a carência de mão-de-obra logo a fará aumentar; e se em algum momento a remuneração for muito alta, a multiplicação excessiva de mão-de-obra logo a fará baixar para sua taxa necessária" (SMITH, 1983, p.102). Em Ricardo, "Quando o preço de mercado do trabalho excede o preço natural, a condição do trabalhador é próspera e feliz, e ele pode desfrutar de grande quantidade de bens de primeira necessidade e dos prazeres da vida, e, portanto, sustentar uma família saudável e numerosa. Quando, entretanto, pelo estímulo que os altos salários dão ao aumento populacional, cresce o número de trabalhadores, os salários baixam outra vez até seu preço natural” (RICARDO, 1982, p.82).
} 
salários. O mercado de trabalho ajustava-se, assim, automaticamente, graças à operação de um mecanismo demográfico, mantendo o salário sempre próximo ao nível de subsistência ${ }^{15}$.

Para Marx, esse ajuste nada tem haver com a realidade demográfica, mas com a realidade da produção, com a forma através da qual, em sua expansão e diversificação, essa recruta ou expulsa os trabalhadores da atividade. O desenvolvimento do modo de produção capitalista, que tem na sua base o uso (numa escala cada vez maior) de maquinas e equipamentos (capital fíxo) no processo de produção, fez com que caísse drasticamente a necessidade de usar trabalho humano (capital variável) ${ }^{16}$, criando, deste modo, "uma população trabalhadora supérflua relativamente, isto é, que ultrapassa as necessidades médias de expansão do capital, tornando-se, desse modo, excedente" (MARX, 2006, p.733). Trata-se da sua famosa tese da superpopulação relativa ou do exército industrial de reserva. No capitalismo, graças à intensa participação do capital fixo, criou-se um excedente de força de trabalho ou um exército industrial de reserva e a oferta de mão de obra emancipou-se da dinâmica demográfica, sendo ora absorvida e ora liberada, de acordo com o ritmo e o perfil da acumulação ${ }^{17}$. A moderna indústria capitalista criou, assim, uma reserva ou excedente de mão de obra, que se expande ou se contrai de acordo com as transformações e os ciclos da acumulação, mas que mantém a relação entre oferta e procura sempre num patamar que impede os salários de afastarem-se do nível de subsistência. O mercado de trabalho "não é, portanto, determinado pelos movimentos do número absoluto da população, mas pela proporção em que a classe trabalhadora se divide em exército ativo e de reserva, pelo aumento ou diminuição do volume relativo da superpopulação, pelo grau em que é absorvida ou liberada" (MARX apud ROSDOLSKY, 2011, p.249), ou seja, "oferta e procura de trabalho são variáveis dependentes da expansão e contração do capital” (MARX, 2006, p.741).

Para Marx, portanto, e também para nós, o mercado de trabalho não se determina pela população, mas pela acumulação. E a própria natureza das duas tendências que determinaram o mercado de trabalho na Era Lula nos induz a adotar essa posição. Apontamos acima que uma queda na taxa de participação foi a causa da queda no ritmo de crescimento da PEA e a taxa de participação é uma variável que depende da realidade econômica e/ou sociocultural e não da realidade demográfica ${ }^{18}$. Um estudo do Banco Central do Brasil (BCB) confirma essa relação entre a tendência de queda no ritmo de crescimento da PEA entre os 1990 e 2000 e a taxa de participação ao demonstrar que sua contribuição para o aumento da PEA cai quase $80 \%$, ao passo que a contribuição do crescimento demográfico cai menos de $10 \%$ (BCB, 2012, p.96). Trata-se claramente de uma tendência associada à participação e não à população, o que, em consequência, associa-a à realidade econômica, já que não houve nesse período nenhuma grande mudança de caráter sociocultural. A relação da tendência de expansão do emprego formal com a atividade econômica é mais explícita, já que se trata em $90 \%$ dos casos de uma forma de ocupação vinculada a empresas, ou seja, vinculada a unidades produtivas cuja finalidade é vender sua produção no mercado para obter lucro. A

\footnotetext{
${ }^{15}$ É o valor do salário suficiente para permitir o trabalhador e sua família apenas sobreviverem, o mínimo.

16 “Com o progresso da acumulação, varia a relação entre capital constante e capital variável. De 1:1 originalmente, ela passa, digamos, para 2:1, 3:1, 4:1, 5:1, 6:1, 7:1. Desse modo, ao crescer o capital, emprega-se em força de trabalho, em vez de 1:1, progressivamente, 1:2, 1:3, 1:4, 1:5, 1:6 e 1:7 [...] Sendo a procura de trabalho determinada não pela magnitude do capital global, mas pela magnitude de as parte variável, ela cai progressivamente com o aumento do capital global" (Marx, 2006, p.732-733).

17 “A população trabalhadora, ao produzir a acumulação de capital, produz, em proporções crescentes, os meios que fazem dela, relativamente, uma população supérflua. Esta é uma lei da população peculiar ao modo capitalista de produção. Na realidade, todo modo histórico de produção tem suas leis próprias de população, validas dentro de limites históricos" (Marx, 2006, p.734-735).

${ }^{18}$ Segundo Wajnman, a "componente de crescimento da PEA dada pela variação nas taxas de atividade é a mais complexa de ser prevista, uma vez que depende não só das condições gerais do mercado de trabalho (nível de emprego, salário real, etc.) mas também de fatores institucionais e s6cio-culturais que afetam o comportamento dos segmentos populacionais específicos" (Wajnman, 1997, p.13).
} 
natureza das duas tendências do mercado de trabalho em questão nesta seção vincula-as, portanto, à dinâmica econômica e, dessa maneira, reforça a posição assumida aqui, que é a de procurar suas causas na lógica da acumulação.

E, de acordo com Marx, a acumulação exerce sua influência no mercado de trabalho de duas maneiras: pela sua magnitude de variação e pela sua composição. No que se refere à magnitude de variação, o autor está tratando do aspecto meramente quantitativo, do tamanho do crescimento, estagnação ou decrescimento (recessão) da economia, ou seja, das "fases de atividade média, de produção a todo vapor, de crise e de estagnação" (MARX, 2006, p.736). Já no que se refere à composição da acumulação, trata-se do seu aspecto qualitativo, do perfil dos investimentos executados, se os mesmos são compostos de capital fixo, trabalho ou recursos naturais, ou seja, trata-se do que Marx chamou de "composição orgânica do capital" (MARX, 2006, p.734).

A acumulação, portanto, determina a oferta e a procura de força de trabalho por meio do seu ritmo de crescimento e do seu perfil. Vejamos então como esses dois aspectos da acumulação se manifestaram no período aqui em questão.

É praticamente unânime o reconhecimento de que a aumento do ritmo de crescimento da economia brasileira nos anos 2000 influenciou decisivamente o mercado de trabalho e as condições de ocupação (BALTAR, 2015; KREIN et al., 2010; CARDOSO JR, 2007; BALTAR, MORETO e KREIN, 2006). Conforme coloca Baltar, "um crescimento do produto interno bruto (PIB) mais vigoroso e com inflação mais baixa, a partir de 2004, aumentou a geração de empregos assalariados, contribuiu para a formalização dos contratos de trabalho e elevou o poder de compra" (BALTAR, 2015, p.07). O ritmo de crescimento da acumulação acelerou-se a partir de 2004 e manteve-se alto até 2011, com a exceção do ano de 2009, quando o país sentiu os efeitos da crise financeira de $2008^{19}$. Em 2012 e 2013 esse ritmo diminui e em 2014 fica praticamente estagnado ${ }^{20}$, com o país já entrando na recessão que marcará 2015 e 2016.

Ao todo, entre 2003 e 2014, a economia cresceu aproximadamente 42\%, o que representa um crescimento anual médio da ordem de 3,5\% ${ }^{21}$. Entre 1992 e 2003 o crescimento econômico total foi de $30 \%$, com uma média anual de 2,5\%. Comparando um período com o outro (Tabela 04), temos um crescimento econômico $40 \%$ maior, o que sem dúvida influenciou a evolução do mercado de trabalho, contudo, em especial no que se refere ao ritmo de expansão do emprego com carteira, os resultados entre os dois períodos são muito discrepantes em relação a essa diferença no ritmo do crescimento econômico: a expansão do emprego com carteira foi $135,74 \%$ maior, passando de $22,05 \%$ entre $1992-2003$ para $51,98 \%$ entre 2003-2014.

Tabela 04- Variação relativa em 92 e 03 e 03 e 14 e variação relativa da variação relativa entre 92-03 e 03-14 do PIB e do emprego com carteira.

\begin{tabular}{|c|c|c|c|}
\hline & $\mathbf{\Delta 9 2} \rightarrow \mathbf{0 3}$ & $\mathbf{\Delta 0 3 \rightarrow 1 4}$ & $\boldsymbol{\Delta}(\boldsymbol{\Delta} \mathbf{0 3} \rightarrow \mathbf{1 4}) \rightarrow(\mathbf{\Delta ~ 9 2 \rightarrow 0 3 )}$ \\
\hline Crescimento PIB & $30,00 \%$ & $42,00 \%$ & $+40,00 \%$ \\
\hline Crescimento Emp. c/ carteira & $22,05 \%$ & $51,98 \%$ & $+135,74 \%$ \\
\hline
\end{tabular}

Fonte: PNAD/IPEA. Elaboração Própria.

Temos, assim, uma diferença de ritmo de crescimento de mais de 200\%. Passamos de um período em que o emprego com carteira cresceu num ritmo inferior ao produto para um período no qual o emprego com carteira cresceu num ritmo superior ao produto. Isso nos

\footnotetext{
${ }^{19}$ Para detalhes sobre as fases do crescimento econômico na Era Lula, cf. Mattos (2015) ou Baltar (2015).

${ }^{20}$ Para detalhes sobre essa retração durante o governo Dilma, cf. Lobo e Anze (2017) ou Carvalho (2018).

${ }^{21}$ Todas as informações sobre crescimento econômico são do Sistema de Contas Nacionais do IBGE e foram retiradas do Ipeadata. http://www.ipeadata.gov.br/Default.aspx. Acesso em 10 de março de 2018,
} 
induz a concluir que a mudança de magnitude de variação ou o aspecto meramente quantitativo do crescimento econômico é insuficiente para explicar o aumento do emprego com carteira (e também a queda na expansão da PEA, como veremos), já que o mesmo não só passou a aumentar num ritmo superior ao produto, como também se reverteu uma realidade em que essa forma de ocupação crescia menos que produto. A composição da acumulação teve aí, portanto, um papel determinante.

A composição da acumulação é algo difícil de se mensurar - ainda mais se formos entrar nos detalhes da conceituação de $\operatorname{Marx}^{22}$ - e não há atualmente um indicador oficial, específico, sobre o tema, entretanto, alguns economistas têm se utilizado de operações econométricas para decompor o crescimento econômico do país, o que pode nos dar uma imagem da composição da acumulação durante a Era Lula.

Segundo Macedo (gráfico 03), "é possível constatar que no Brasil o crescimento do PIB nesse período [2001 a 2011] foi mais puxado pelo aumento do pessoal ocupado (70\%) do que pelos ganhos de produtividade (30\%)" (MACEDO, 2014, p.107). Esse desempenho contrasta com o observado entre 1940-2000, quando, segundo Bacha e Bonelli (BACHA e BONELLI, 2001, p.4), os ganhos de produtividade explicaram 56\% do crescimento do PIB da economia brasileira e a ocupação $44 \%$.

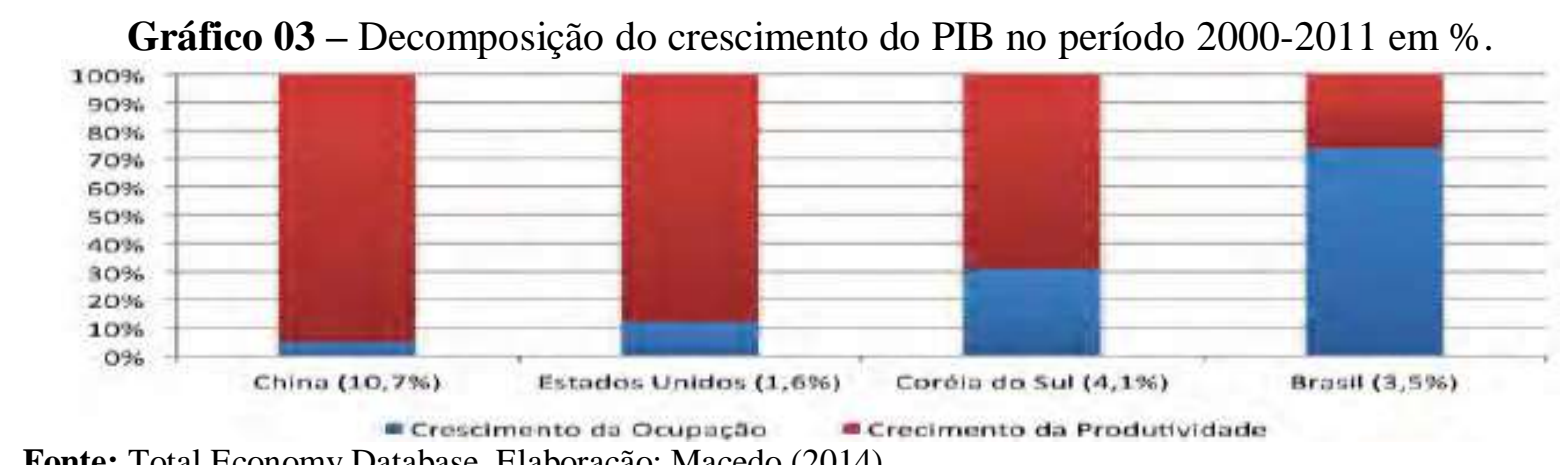

Fonte: Total Economy Database. Elaboração: Macedo (2014).

Em outro trabalho, Cavalcante e de Negri (2014) rementem-se a uma equação usada por Bonelli (2005) para decompor o crescimento do PIB per capita entre 1992 e 2001 e entre 2001 e 2009, e, com base em dados da PNAD e do SCN, constatam que:

A diferença fundamental entre os dois períodos diz respeito aos fatores que mais explicam o crescimento do PIB per capita. Enquanto mais de $90 \%$ do crescimento no período 1992-2001 se deveu à produtividade do trabalho, no período 2001-2009 apenas pouco mais da metade do crescimento do PIB per capita foi explicado pelos ganhos de produtividade, e o restante foi devido ao aumento das taxas relacionadas ao mercado de trabalho. Assim, as taxas médias de crescimento da produtividade nos períodos 1992-2001 e 20012009 são muito semelhantes, mas, no segundo período, a contribuição das variáveis relacionadas ao mercado de trabalho e a variáveis demográficas (que, na década anterior, havia se limitado a menos de 7\%) é superior e explica o crescimento mais acelerado do PIB per capita. Desse modo, foram a incorporação de um grande contingente populacional ao mercado de trabalho e a redução dos níveis de desemprego que explicaram uma parcela significativa do crescimento do PIB per capita no período entre 2001 e 2009. (CAVALCANTE e DE NEGRI, 2014, p.149)

\footnotetext{
${ }^{22}$ Sobre esses detalhes, cf. A composição do capital: uma sugestão de interpretação, de Araujo (2017).
} 
Para concluir essa exposição, gostaríamos de mencionar ainda um interessantíssimo indicador, proposto por Bacha e Bonelli (2013), para expressar a relação mão de obra/capital em uso. No cálculo dos autores, o indicador segue uma trajetória declinante contínua de 1947 até 2001, com o crescimento do uso do capital sempre superior ao do uso do trabalho (BONELLI; BACHA, 2013, p. 245). De 2003 a 2009 pela primeira vez rompe-se essa trajetória e se inverte a relação de ordem, com o uso do trabalho superando o do capital em praticamente todo o período (Ibidem).

Os três trabalhos mencionados acima indicam duas coisas: a participação dominante do emprego do fator trabalho no crescimento econômico nos anos 2000 e um significativo crescimento dessa participação em relação aos anos 1990. Com base nessas informações, podemos então afirmar que, durante a Era Lula, vigorou um modelo de acumulação relativamente (vis-à-vis os resultados no período 92-03) intensivo na participação do fator trabalho, ou seja, um modelo em que o trabalho dominou a combinação produtiva dos fatores envolvidos na acumulação.

Assim, de acordo com a análise feita até aqui nesta subseção, podemos afirmar que um aumento na magnitude do crescimento econômico e, sobretudo, a entrada em vigor de um perfil de acumulação mais intensivo na participação do fator trabalho foram os responsáveis pelo forte crescimento do emprego com carteira. E, como vimos mais acima, a queda no ritmo de crescimento da PEA associou-se à realidade econômica, o que nos permite afirmar que a diminuição no ritmo de crescimento da PEA também foi resultado da composição e da magnitude de variação da acumulação. No Gráfico 02 podemos observar que a variação anual da PEA vai declinando à medida que vai crescendo e se consolidando a oferta de empregos formais.

Concluímos, portanto, com base na análise feita nesta subseção, que as tendências que dominaram o mercado de trabalho na Era Lula resultaram de um perfil de acumulação intensivo na participação do trabalho e moderadamente mais intenso em sua magnitude de variação.

\subsection{Gênese Político-Econômica}

A identificação dos fatores político-econômicos que estão na gênese do perfil de acumulação observado acima passa, essencialmente, pela seguinte premissa: "a variação do volume da demanda global e a variação de sua composição condicionam a composição da oferta e, portanto, a escolha da combinação produtiva dos fatores envolvidos na inversão" (FURTADO e SOUZA, 1970, p. 475). Colocamo-nos aqui, assim, em linha com a visão de Furtado, que vê a composição da demanda, e não meramente a sua magnitude de variação, como algo determinante para o emprego, pois essa composição condiciona a acumulação, ou melhor, condiciona a combinação de fatores envolvidos nas inversões.

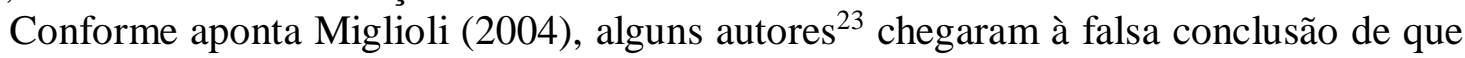
a acumulação, para Marx, não tinha relação com a dinâmica da demanda efetiva, supondo, inclusive, que ele seguia a Lei de $\mathrm{Say}^{24}$, contudo:

Essa interpretação é totalmente infundada. Marx devotava grande desprezo por Say e por sua "lei dos mercados" e não perdoava Ricardo por tê-la adotado. Podemos afirmar que foi precisamente ao criticar a versão ricardiana dessa "lei" aplicada à análise do processo capitalista de

\footnotetext{
${ }^{23}$ Como Tugan-Baranóvski, Lenin e a própria Luxemburgo em uma passagem (MIGLIOLI, 2004, p.13).

${ }^{24}$ A ideia de que a acumulação cria de maneira imediata a procura necessária para realizá-la ou consumi-la, ou de que, como se tem dito desde Keynes, "a produção cria sua própria demanda" (1988).
} 
acumulação que Marx começou a formular sua concepção a respeito da importância da realização da mais-valia. (MIGLIOLI, 2004, p.14)

Marx, portanto, por mais que não tenha se preocupado em formular uma teoria da demanda efetiva, reconhece "a existência do problema da demanda (ou realização) no processo de acumulação de capital" (MIGLIOLI, 2004, p.121) e dá, em sua obra, uma contribuição decisiva para o reconhecimento dessa relação ${ }^{25}$ (MIGLIOLI, 2004, p.133). Analisar a acumulação a partir da dinâmica da demanda não é, assim, incoerente com o entendimento de Marx, apesar deste não expor de maneira enfocada essa relação.

A particularidade com a qual Furtado entende tal relação é resultado de sua aptidão única para absorver a especificidade estrutural das economias subdesenvolvidas, entretanto, o acolhimento teórico dessa especificidade não quebra a essência da relação lógica entre demanda e acumulação tal como entendida por Marx, apenas a decompõe para melhor identificar o seu funcionamento, nessa realidade específica. E tal decomposição ${ }^{26}$, como antecipado acima, vai ao sentido de se perceber "a influência das variações na composição da demanda sobre a produtividade e o emprego" (FURTADO e SOUZA, 1970, p. 464), ou seja, de se diferenciar qualitativamente as variações na demanda, por terem esses diferentes perfis de variação efeitos diversos sobre a acumulação e o emprego. Spaventa, citado por Furtado (Ibidem), defende que "em modelos agregados, mudanças que ocorrem por dentro [within] nas variáveis e que não necessariamente alteram o seu valor agregado total são negligenciadas" (SPAVENTA, 1967, p.178), e no caso da demanda, uma maior desagregação é importante porque "os vários setores da economia têm diferentes níveis de produtividade e de progresso técnico" (SPAVENTA, 1967, p.178-179) e, por isso, operam com diferentes coeficientes de uso dos fatores, o que faz com que os resultados a nível de emprego e produto sejam diferentes segundo o setor em que se manifeste a variação (SPAVENTA, 1967, p.179).

A variação na demanda agregada, durante a Era Lula, resultou, sobretudo, de um aumento do consumo das pessoas da parte de baixo da pirâmide social, tendo, assim, tal variação, um perfil particular, centrado nos setores de bens e serviços de consumo de massa,

\footnotetext{
25 "A criação desta mais-valia constitui o processo direto de produção [...] Logo que se incorpora em mercadorias todo o sobretrabalho que foi possível extrair, a mais-valia está produzida. Mas esta produção de mais-valia conclui apenas o primeiro ato do processo capitalista de produção - o processo direto de produção [...] Agora vem o segundo ato do processo. Todo o volume de mercadorias, isto é, o produto total - incluindo a parte que repõe o capital constante e o variável, e a parte que representa a mais-valia - precisa ser vendido [...] As condições de exploração direta e as condições de realiza-la não são idênticas. Elas divergem não apenas em lugar e tempo, mas também logicamente. As primeiras são limitadas somente pela capacidade produtiva da sociedade, e as segunda pela relação proporcional dos vários ramos de produção e pela capacidade de consumo da sociedade" (MARX apud MIGLIOLI, 2004, p.122).

${ }^{26}$ Por ter Keynes se tornado a grande referência na exposição da relação entre o emprego, a acumulação e a demanda, a proposta furtadiana de se abordar de maneira desagregada a demanda efetiva se dá em diálogo com ele. Segundo Furtado, "Preocupado com os fatores determinantes a curto prazo do nível de emprego, emprestou um papel paramétrico a uma série de variáveis e [...] dados esses elementos, cabia demonstrar que outras variáveis respondem pelas flutuações no nível de emprego. Dentre estas, Keynes destacou o montante das inversões, cujos determinantes passaram a preocupá-lo diretamente. Havendo atribuído o papel de variável básica ao nível das inversões, Keynes daí não inferiu todas as consequências necessárias" (FURTADO, 1983, p. 53); "o nosso estudo segue uma linha neokeynesiana" (FURTADO e SOUZA, 1970, p.464). Em suma, segundo Furtado, Keynes propõe uma relação de causalidade demasiadamente geral entre o volume das inversões e o nível de emprego, assumindo como dados uma série de fatores que possibilitam que se manifeste o efeito multiplicador; no entanto, tais fatores, não necessariamente se manifestam em economias subdesenvolvidas. A solução desse problema passa por uma maior desagregação da demanda e da acumulação por ela incentivada e serve para apontar "a importância que têm a distribuição de renda e a diversificação do consumo" (FURTADO, 1970, p.463). Sobre esta questão ver também Investimento, renda e o multiplicador numa economia subdesenvolvida, de Rao (2010).
} 
perfil que, por sua vez, estimulou um perfil particular de acumulação, marcado, como vimos, por uma elevada participação relativa do fator trabalho. Em uma pesquisa seminal para entender a dinâmica da acumulação no período, Medeiros aponta que:

As principais transformações ocorridas de renda no período - e que são importantes para a análise do padrão de consumo - foram a elevação do poder de compra dos $25 \%$ mais pobres e a mudança da distribuição das famílias por níveis de renda. Neste sentido, destaca-se o aumento de $30 \%$ na renda dos $50 \%$ mais pobres [...] a elevação da renda familiar per capita entre os $25 \%$ mais pobres, dos $50 \%$ mais pobres (com renda familiar de 2 a $3 \mathrm{SMs}$ e de 3 a 5 SMs) e dos $25 \%$ subsequentes (a baixa classe média). (MEDEIROS, 2015, p. 68).

Medeiros demonstra que, com essa evolução da renda, houve um deslocamento no perfil de consumo da sociedade brasileira, com um forte aumento na participação das despesas com transporte, higiene e cuidados pessoais, assistência à saúde, serviços e eletrodomésticos, os quais, entre 2003 e 2009 cresceram 6,5\%, 10,1\%, 11,0\%, 10,2\% e 4,1\%, respectivamente, bem acima da média da economia (MEDEIROS, 2015, p. 70).

O comportamento linear entre a evolução da distribuição da população entre as classes econômicas (gráfico 4) e a evolução do consumo das famílias entre componentes da demanda (gráfico 5) ajudam a explicitar a composição da demanda da Era Lula.

Gráfico 04: Pirâmide Populacional e Classes Econômicas 2003, 2009, 2011 e 2014.

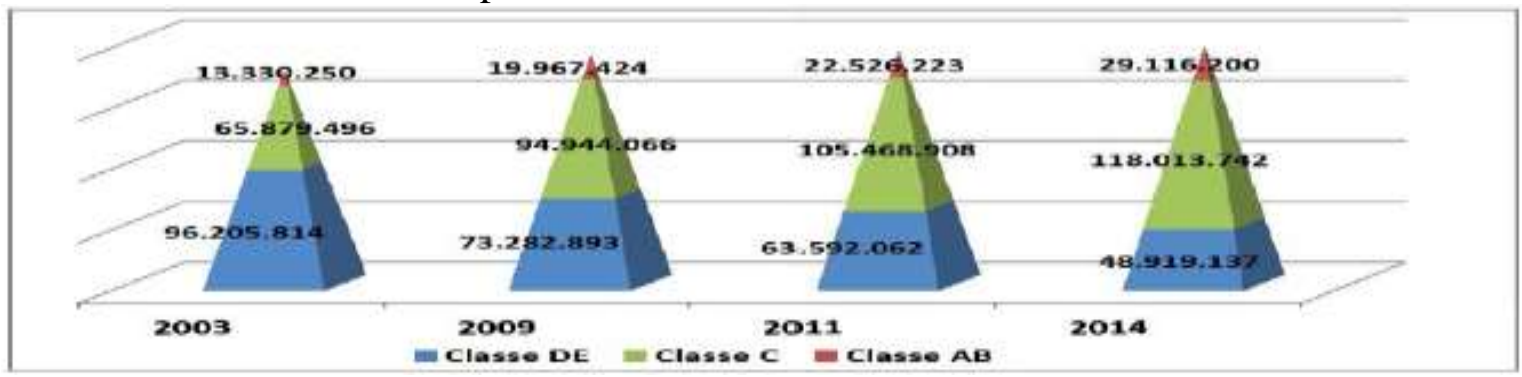

Fonte: PNAD/IBGE. Elaboração: Neri (2014).

Gráfico 05: Contribuição ao crescimento por componentes da demanda (1995-2012).

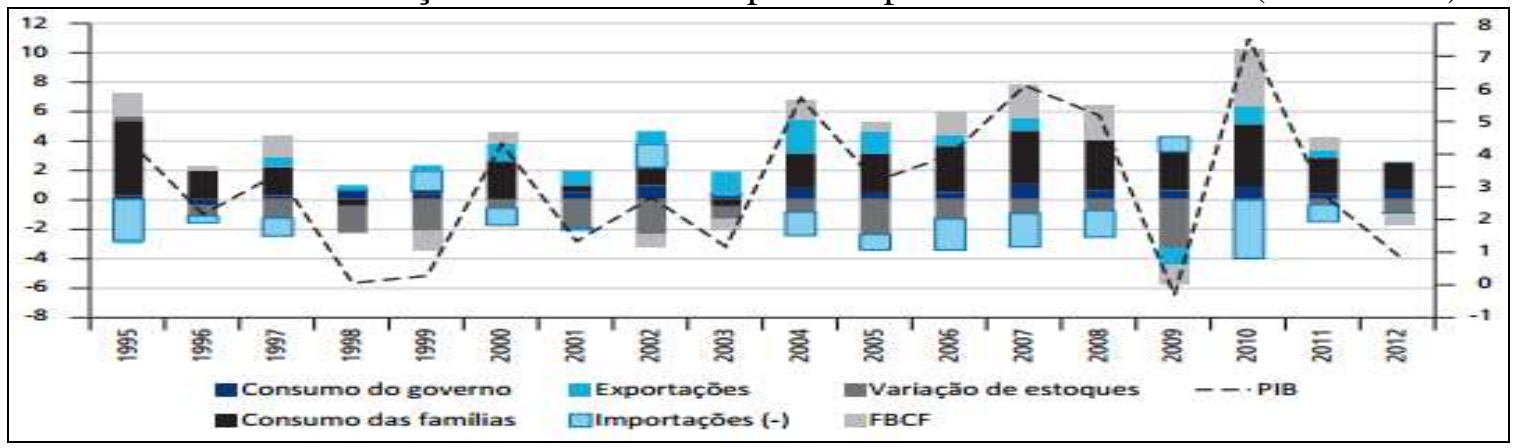

Fonte: Ipeadata. Elaboração: Amitrano (2015).

O reflexo dessa composição da demanda na dinâmica do produto é explícito: entre 2003 e 2013, segundo indicador do IPEA ${ }^{27}$ feito com base nas contas nacionais, o produto do setor de serviços cresce $38,36 \%, 33 \%$ a mais que a indústria (que cresce $28,86 \%$ no período) e $25 \%$ a mais que a agropecuária (que cresce 30,86 no período). Devido ao grau de participação do trabalho no setor de serviços, em nível de emprego, essa discrepância, que já se destaca no produto, é bem maior. Os serviços, que engloba também o comércio e parte da administração

\footnotetext{
${ }^{27}$ http://www.ipeadata.gov.br/Default.aspx. Acesso em 17 de março de 2018.
} 
pública, tiveram uma variação no emprego formal quase $60 \%$ maior do que a indústria e quase $95 \%$ maior do que a agropecuária.

Gráfico 06 - Saldo líquido de Empregos Formais 2004-2013

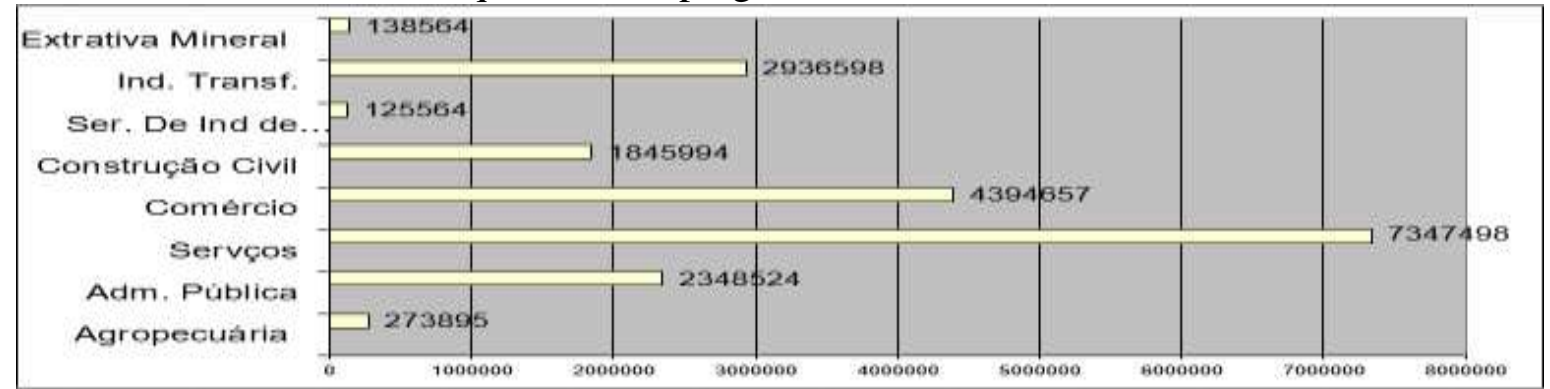

Fonte: RAIS/MTE. Elaboração: Própria.

Para Furtado, que viveu até 2004, a economia brasileira sempre conviveu com uma baixa capacidade de absorção de mão de obra - o que reproduziu um excedente estrutural de mão de obra ${ }^{28}$, mesmo com taxas elevadas de crescimento econômico, e o grande motivo disso, para ele, é a estagnação do perfil da procura interna, concentrada nas demandas das classes A e B, reflexo de nossa perversa estrutura de distribuição de renda. Para Furtado, portanto, a economia brasileira marca-se por uma baixa capacidade de absorção de mão de obra e isso está associado à reprodução de um perfil de demanda concentrado, que inibe a expansão da produção e comercialização doméstica de bens e serviços de consumo e estimula a importação e inversões domésticas em setores com alta capitalização (indústria de bens duráveis e agroindústria exportadora). Assim, a elevação do nível de renda da população e a diversificação do consumo teriam, para ele, "maior significação para a absorção do excedente estrutural de mão de obra do que uma intensificação do processo de formação de capital" (FURTADO, 1983, p.153). Trata-se, assim, claramente, de uma avaliação pautada pela relação entre perfil da demanda/perfil da acumulação.

O perfil da demanda doméstica da economia brasileira, ao longo do século XX, esteve vinculado à procura das classes mais altas, o que fez com que o fluxo de renda aplicado no abastecimento dessa demanda direcionasse-se à importação de produtos ou à adoção interna de combinações produtivas altamente capitalizadas e poupadoras de mão de obra. A melhoria da renda das classes menos favorecidas estimulou a procura e o comércio de serviços e bens de consumo de massa, cuja oferta é essencialmente doméstica e marcada, sobretudo no setor de serviços e no comércio, por um baixo nível de capitalização e alta participação do fator trabalho. Tal como argumenta Furtado:

Se a demanda dos "mais ricos" se acentua e há, em consequência, maiores solicitações de bens que são produto de técnicas de produção de nível tecnológico relativamente mais elevado e mais capitalizadas, as novas inversões serão relativamente mais capitalizadas de como seriam com intensificação da demanda dos "menos ricos", a qual se manifestaria pela difusão de bens de consumo com técnicas de produção correntes e menos capitalizadas. (FURTADO e SOUZA, 1970, p. 477)

O perfil da variação da demanda foi, assim, essencial para o perfil da acumulação que vigorou durante a Era Lula. Contudo, para que a acumulação, incentivada por uma determinada composição da procura, possa reproduzir-se, é preciso haver uma compatibilidade com a disponibilidade dos fatores requeridos, ou melhor, a elasticidade na curva da oferta de fatores

\footnotetext{
${ }^{28}$ Para Ramos a lógica do conceito de excedente estrutural é a mesma do exercito industrial de reserva (RAMOS, 2012, p.376).
} 
de produção relacionados às inversões requeridas também é um fator de importância fundamental. Como vimos na primeira seção, o principal fator demandado pelas inversões estimuladas pela evolução da demanda durante a Era Lula foi justamente o trabalho, o que é lógico, haja vista o elevado crescimento do setor de serviços, do comércio, da construção de edifícios e do setor de bens de consumo não duráveis, setores de baixa capitalização. A evolução do perfil da demanda no período estimulou, portanto, a procura por força de trabalho, mais especificamente uma força de trabalho urbana e de baixa qualificação, da qual dispomos em abundância e a baixos custos relativos. Tal fato contribuiu para que as limitações impostas pelos típicos problemas de capacidade produtiva da economia brasileira, tais como infraestrutura e capital humano, por exemplo, pudessem ser temporariamente mitigados. Além disso, é preciso destacar, no que se refere a esse ponto, a importância da queda do dólar e os incentivos à agricultura familiar e à produção de alimentos, o que ajudou a segurar a inflação e, consequentemente, a elevação dos custos de remuneração do fator trabalho ${ }^{29}$.

É preciso ressaltar que a constatação feita aqui, sobre a elasticidade na curva de fatores não se aplica ao setor industrial, o qual, até o ano de 2009 respondeu de maneira importante ao estímulo dado pela evolução da demanda, mas a partir de então, devido, sobretudo, à interação entre a valorização do cambio, o aumento da competitividade internacional, ao aumento do custo de reprodução da mão de obra, iniciou um trajetória de regressão que se arrasta até os dias atuais ${ }^{30}$.

Foi, portanto, a composição do crescimento da demanda, aliado a uma alta disponibilidade dos fatores requeridos pelas inversões que responderam a tal crescimento, o que, em nossa visão, fundamentou o perfil de acumulação vigente na Era Lula e os resultados deste no mercado de trabalho e nas condições de ocupação. Depois da divulgação de inúmeras pesquisas, entre as quais gostaríamos de destacar as de Carvalho (2018), Medeiros (2015), Baltar (2015), Lobo (2014), Modenesi e Paula (2013) e Barbosa e Souza (2010), parece hoje estar clara a responsabilidade da atuação do Estado, através das políticas econômica e social, sobre esse perfil particular de crescimento da demanda. Apesar do papel decisivo desempenhado pelo cenário externo, que elevou a arrecadação do governo e criou o espaço fiscal necessário para a expansão dos investimentos públicos e das políticas de transferência de renda, foram as decisões do governo de se implementar um conjunto de medidas o que desencadeou o crescimento da demanda no perfil descrito acima. Entre essas medidas, destacam-se as seguintes: i) o Programa Bolsa-Família; ii) a política de valorização do salário mínimo; iii) o aumento da oferta de crédito; iv) as políticas de incentivo à agricultura familiar; e v) a expansão do investimento público. Como o material hoje existente já é muito rico, não vamos nos alongar aqui demonstrando a importância de cada uma dessas medidas, e com isso, encerramos esta seção.

\footnotetext{
${ }^{29}$ Reconhecemos que uma melhoria na eficiência e a adoção de uma postura mais ativa, adotada a partir da segunda metade dos anos 1990, por parte de instituições como a Receita Federal, o Ministério Público do Trabalho, o Ministério do Trabalho, o Ministério da Previdência e a Justiça do Trabalho, conforme destaca Baltar (2015), foi importante para o avanço do emprego formal, contudo, para nós, esse avanço é essencialmente um fato político-econômico, isto é, um fato de que deriva da compatibilidade entre o estímulo a um perfil de acumulação com alta participação relativa do fator trabalho, mais especificamente uma força de trabalho de baixo custo e baixa qualificação, e a oferta abundante de mão de obra desqualificada e disposta a aceitar uma remuneração próxima do salário mínimo.

${ }^{30}$ Para maiores informações sobre essa questão cf. Desindustrialização: conceituação, causas, efeitos e o caso brasileiro, de José L. Oreiro e Carmem A. Feijó (2010).
} 


\section{CONCLUSÃO}

O que define a economia política do trabalho na Era Lula é a compatibilização entre o perfil da variação da demanda e disponibilidade dos fatores requeridos pelas inversões estimuladas por esse perfil.

A variação da demanda agregada, centrada no consumo das famílias, mais especificamente no consumo das famílias da parte de baixo da pirâmide social (classes C, D e E) estimulou inversões em segmentos - predominantemente nos setores de serviços, comércio e construção civil - com alta participação relativa do trabalho. A força de trabalho requerida por esses segmentos, entretanto, foi especificamente daquele tipo que estruturalmente existe em excesso no Brasil, de baixa qualificação e disposta a receber uma remuneração próxima do salário de subsistência (mínimo).

Podemos afirmar que, em geral, o cerne do esforço político-econômico dos governos Lula e Dilma foi para manter compatível esse gênero de variação da demanda e a oferta de trabalho por ele requerida. Ao mesmo tempo em que se implementavam medidas de estímulo à demanda, como as transferências de renda, a valorização do mínimo e os investimentos públicos, manteve-se um atento controle da inflação, que se deu graças à valorização cambial, a uma política monetária predominantemente rígida e ao estimulo à produção de alimentos, $o$ que, apesar de algumas exceções, sobretudo no sul do país, manteve sob controle o custo de reprodução do trabalho e, consequentemente, a sua disponibilidade ${ }^{31}$.

O principal resultado desse programa político-econômico foi o agudo crescimento do emprego com carteira assinada, o que, em conjunto com o aumento moderado do emprego público e do forte crescimento da rentabilidade do trabalhado por conta própria (e também em conjunto com as políticas de fomento do ensino técnico e superior, que fortaleceram a tendência de queda na participação dos jovens que vinha desde os anos 90) levou à queda na taxa de participação ao longo do período, o que fez com que o crescimento da PEA diminuísse de ritmo. A coincidência desses dois movimentos dentro do mercado de trabalho, um pelo lado da demanda e outro pelo lado da oferta, fez com que melhorassem sistematicamente as condições de ocupação da população brasileira no período, o que, por sua vez, foi o substrato do processo de inclusão social que marcou a Era Lula.

Para finalizar, gostaríamos de dizer que consideramos o destaque da composição da demanda como a principal contribuição deste texto, haja vista toda a repercussão que a mesma teve sobre a acumulação, o emprego e as condições de ocupação. Assim, defendemos a necessidade de se considerar, tal como Spaventa, "a composição da demanda como uma variável de política econômica" (SPAVENTA 1967, p.192). Esperamos que a análise apresentada aqui possa, em alguma medida, ter ajudado a sustentar essa posição.

\section{Referências bibliográficas}

AMITRANO, C. "Um mapa setorial do emprego e dos salários a partir de dados da RAIS". Textos para Discussão IPEA, n. 2033, p. 1-87. 2015.

ARAUJO, E. “A composição do capital: uma sugestão de interpretação". Crítica Marxista, n.44, pp.87-107. 2017.

\footnotetext{
${ }^{31}$ A perda de controle na busca por essa compatibilidade, através da imposição de freios exagerados à demanda no início do mandato e de uma estratégia equivocada para reaquece-la posteriormente, foi o que fez com o primeiro governo Dilma levasse à retração a economia do trabalho da Era Lula (LOBO e ANZE, 2017).
} 
BACHA, E.; BONELLI, R. Crescimento e produtividade no Brasil: o que nos diz o registro de longo prazo. Seminários Dimac, n. 42. Disponível em:

$<$ http://www.worldcat.org/title/crescimento-e-produtividade-no-brasil-o-que-nos-diz-oregistro-de-longo-prazo/oclc/51940699\&referer=brief_results>. Acesso: 20/02/2018.

BONELLI, R.; BACHA, E. "Crescimento brasileiro revisitado". In: VELOSO, F. et al. Desenvolvimento econômico: uma perspectiva brasileira. Rio de Janeiro: Elsevier. 2013.

BALTAR, P. "Crescimento da Economia e Mercado de Trabalho no Brasil". In: CALIXTRE, A.; BIANCARELLI, A.; CINTRA, M. (ed.). Presente e futuro do desenvolvimento brasileiro. Brasília: IPEA, 2015.

BALTAR, P.; LEONE, E. “O mercado de trabalho no Brasil nos anos 2000”. Carta Social e do Trabalho, n. 19, pp. 16-39. 2012.

BALTAR, P.; LEONE, E. "Perspectivas para o mercado de trabalho após o crescimento com inclusão social”. Estudos Avançados, v. 85, n. 29, pp.53-67. 2015.

BALTAR, P.; MORETTO, A.; KREIN, J. “O emprego formal no Brasil: início do século XXI". In: KREIN, J. et al. (orgs). As transformações no mundo do trabalho e os direitos dos trabalhadores. São Paulo: LTr, 2006.

BALTAR, P.; SOUEN, J.; CAMPOS, G. "Emprego e distribuição da renda". Texto para discussão Instituo de Economia Unicamp, n. 298, pp. 01-42. 2017.

BANCO CENTRAL DO BRASIL. Impacto das alterações demográficas sobre a taxa de desemprego. Boletim Regional, out. Disponível em:

<https://www.bcb.gov.br/pec/boletimregional/port/2012/10/br201210b1p.pdf>. Acesso em: $15 / 04 / 2018$.

BARBOSA. A. F. “Os avanços da Era Lula”. Interesse Nacional, v. 20, n.01, p. 40-50. 2014.

BARBOSA, N.; SOUZA, J. “A Inflexão do Governo Lula: Política Econômica, Crescimento e distribuição de Renda". In: SADER, E.; GARCIA, M. (orgs). Brasil: entre o Passado e o Futuro. São Paulo: Fundação Perseu Abramo e Editora Boitempo, 2010.

BARROS, R.; HENRIQUE, R.; MENDONÇA, R. “A estabilidade inaceitável: desigualdade e pobreza no Brasil”. In: HENRIQUES, R. (org.). Desigualdade e Pobreza no Brasil. Brasília: IPEA. 2000.

BONELLI, R. “O que causou o crescimento econômico no Brasil?” In: GIAMBIAGI, F. et al. Economia brasileira contemporânea: 1945-2004. Rio de Janeiro: Elsevier. 2005.

CALIXTRE, A.; VAZ, F. (org.). PNAD 2014: Breves análises. Nota Técnica IPEA, n. 22, dez. 2015.

CAMPOS, S. “A questão dos determinantes dos salários nas teorias clássica, marxista e neoclássica”. Ensaios FEE, n.12, v.01, pp.131-157. 1991. 
CARDOSO JR, J. As fontes de recuperação do emprego formal no Brasil e as condições para sua sustentabilidade temporal. Artigo apresentado no $10^{\circ}$ Encontro Nacional da Associação Brasileira de Estudos do Trabalho - ABET, Salvador, 19 a 21 de junho. 2007.

CARDOSO JR, J.; HAMASAKI, C. "Padrões De Desenvolvimento, Mercado De Trabalho E Proteção Social: A Experiência Brasileira Entre As Décadas Liberal (1990) E

Desenvolvimentista (2000)". Texto para discussão IPEA, n. 2021, pp. 01-60. 2015.

CARVALHO, L. Valsa Brasileira: do boom ao caos econômico. São Paulo: Todavia. 2018.

CAVALCANTE, F.; De NEGRI, L. Evolução recente dos indicadores de produtividade no Brasil. In: OLIVEIRA, M.P. et al. (org.). 2014. Rede de Pesquisa Formação e Mercado de Trabalho - Coletânea de Artigos: produtividade e desenvolvimento. Vol. I. Brasília: ABDI; IPEA. 2014.

FAGNANI, E.; CALIXTRE, A. “A política social e os limites do experimento desenvolvimentista (2003-2014). Texto para discussão Instituo de Economia Unicamp, n. 295, pp. 01-38. 2017.

FURTADO, C. Teoria e Política do Desenvolvimento. São Paulo: Abril Cultural. 1983.

FURTADO, C.; SOUSA, A. "Los Perfiles de la Demanda y de La Inversión". Trimestre Econômico, v. 37, n. 147, pp. 463-487. 1970.

HOFFMAN, R. "Desigualdade e pobreza no Brasil no período 1979/97 e a influência da inflação e do salário mínimo”. Economia e Sociedade, v.07, n. 02, pp. 199-221. 1998.

KEYNES, J. M. A Teoria Geral do Emprego, do Juro e da Moeda. São Paulo: Abril Cultural, 1988.

KREIN, J. et al. "Moving towards decent work. Labour un the Lula government: reflections on recent Brazilian experience". Global Labour University Working Papers, n. 9, pp. 1-38. 2010.

LOBO, V. “Dois Dogmas do Lulismo". Política e Sociedade, v. 12, n. 26, pp. 133-161. 2014.

LOBO, V. ANZE, V. “O primeiro governo Dilma e a retração do Lulismo”. Cadernos do Desenvolvimento, v. 12, n. 20, pp. 61-97. 2017.

MACEDO, M. “O que vem acontecendo com a produtividade da economia brasileira?" In: OLIVEIRA, M.P. et al. (org.). 2014. Rede de Pesquisa Formação e Mercado de Trabalho Coletânea de Artigos: produtividade e desenvolvimento. Vol. VI. Brasília: ABDI; IPEA. 2014.

MANDEL, E. A formação do pensamento econômico de Karl Marx. Rio de Janeiro: Zahar. 1968.

MARX, K. O Capital. Vol.2. Rio de Janeiro: Civilização Brasileira. 2006.

MATTOS, F. “Avanços e dificuldades para o mercado de trabalho". Estudos Avançados, v. 29, n. 85, pp.69-85. 2015. 
MEDEIROS, C. Inserção Externa, Crescimento e Padrões de Consumo na Economia Brasileira. Brasília: IPEA. 2015.

MIGLIOLI, J. Acumulação de Capital e Demanda Efetiva. São Paulo: Hucitec. 2004.

MODENESI, A.; PAULA, A.; PIRES, M. “A Tela de Contágio das Duas Crises e as Respostas da Política Econômica". In:ASSOCIAÇÃOKEYNESIANABRASILEIRA. Dossiê da Crise IV: A Economia Brasileira na Encruzilhada. 2013. Disponível em:

<http://www.akb.org.br/upload/141020131857343605_DOSSI\%C3\%8A_Economia_na_encr uzilhada.pdf>. Acesso em: 15/07/2018.

NERI, M. Dynamics of income distribution in Brazil. Artigo apresentado no $25^{\circ}$ Encontro Nacional de Economia, Recife, 10 a 12 de dezembro. 1997.

NERI, M. A década inclusiva (2001-2011): Desigualdade, pobreza e políticas de renda. Comunicado IPEA, n. 155, set. 2013. Disponível em: < http://www.ipea.gov.br/portal/index.php?option=com_content $\&$ view=article $\& i d=15611 \&$ cati $d=161>$. Acesso em: 20/01/2018.

NERI, M. Assuntos Estratégicos: Social e Renda - A classe média brasileira. Brasília: SAE. 2014.

OREIRO, J.; FEIJÓ, C. "Desindustrialização: conceituação, causas, efeitos e o caso brasileiro". Revista de Economia Política, v. 30, n. 2, pp. 219-232. 2010.

RAMOS, C. A. Economia do Trabalho: Modelos Teóricos e Debate no Brasil. Curitiba: CRV. 2012.

RAO, V. "Investimento, renda e o multiplicador numa economia subdesenvolvida". In: AGARWALA, A. SINGH, S. A economia do subdesenvolvimento. Rio de Janeiro: Contratempo, 2010.

ROSDOLSKY, R. Gênese e estrutura de O capital de Karl Marx. Rio de Janeiro: Contraponto. 2011.

RICARDO, D. Princípios De Economia Política E Tributação. Nova Cultura: São Paulo. 1982.

SMITH, A. A Riqueza Das Nações: Investigação Sobre Sua Natureza E Suas Causas. Nova Cultura: São Paulo. 1983.

SPAVENTA, L. "Effects of changes in the composition of demando $\mathrm{n}$ the productivity of labour ando n employment". International Economic papers, n.12, pp. 178-195. 1967.

WAJNMAN, S. "Tendências prospectivas de crescimento da população economicamente ativa no Brasil”. Texto para discussão CEDEPLAR, n.111, pp. 01-31. 1997. 